\title{
CMR evaluation of aorto-pulmonary collaterals in Glenn and Fontan patients
}

\author{
Pierluigi Festa ${ }^{1,2^{*}}$, Lamia Ait Ali ${ }^{3,1}$, Petra Keilberg ${ }^{2}$, Vitali Pak ${ }^{4}$ \\ From 18th Annual SCMR Scientific Sessions \\ Nice, France. 4-7 February 2015
}

\section{Background}

Aorto-pulmonary collaterals (APCs) are frequent in patients with uni-ventricular heart. Their clinical significance remains controversial. Quantitative assessment of APCs blood flow using cardiac magnetic resonance (CMR) have been already validated.

Aim: to evaluate factors associated to APCs flow (QAPCs) evaluated by CMR in Post Glenn and Fontan patients

\section{Methods}

Form our CMR database we identified all patients with previous Glenn or Fontan intervention who underwent a targeted CMR studies from May 2005 to September 2014. QAPCs was calculated using through-plane phase-contrast as QAPCs = (left pulmonary veins flow + right pulmonary veins flow) - (right pulmonary artery flow + left pulmonary artery flow). Values were normalized to body surface area and indexed to aortic flow (QAPCs/aortic flow). Surgical history and clinical status was recorded.

\section{Results}

86 CMR examination in 82 patients (55 Fontan and 31 Glenn, age $14 \pm 11$ ) were included in the study. In 4 patients CMR evaluation was performed before and after Fontan.

QAPCs resulted $1.06 \pm 0.7 \mathrm{l} / \mathrm{min} / \mathrm{m}^{2}$, constituting $29 \pm$ $19 \%$ (range 3-88\%) of systemic blood flow. The amount of QAPCs in Glenn patients resulted higher than in Fontan patients (respectively $1.26 \pm 0.58 \mathrm{l} / \mathrm{min} / \mathrm{m}^{2}$ vs $09 \pm 0.7$ $1 / \mathrm{min} / \mathrm{m} 2, \mathrm{p}=0.03$ ). The QAPCs was independent of the morphology of the systemic ventricle and the anatomical diagnosis except for hypoplastic left heart syndrome in the Glenn group $\left(1.7 \pm 0.38 \mathrm{l} / \mathrm{min} / \mathrm{m}^{2}\right.$ vs $1.13 \pm 0.58 \mathrm{l} / \mathrm{min} / \mathrm{m}^{2}$ in

'Pediatric cardiology and GUCH unit, Toscany Fondation Gabriel Monasterio, Massa, Italy

Full list of author information is available at the end of the article all other patients, $\mathrm{p}=0.02$ ). In the whole population, QAPCs inversely correlates with age at CMR study $(\mathrm{r}=-$ $0.21, \mathrm{P}=0.001)$, with peripheral 02 sat $(\mathrm{r}=-0,38, \mathrm{P}<0.001)$, with Right Pulmonary Artery (RPA) diameter, cross sectional area and flow (respectively $\mathrm{r}=-0.18 \mathrm{P}=0,03, \mathrm{r}=-0.15$, $\mathrm{P}=0,02, \mathrm{r}=-0.4, \mathrm{P}<0,001)$, as well as with Left Pulmonary Artery (LPA) diameters $(r=-0.43, \mathrm{P}<0.001)$, cross sectional area $(\mathrm{r}=-0.41, \mathrm{P}<0.001)$ and flow $(\mathrm{r}=-0.49, \mathrm{P}<0.001)$; QAPCs directly correlates with cardiac output $(\mathrm{r}=0.51$ $\mathrm{P}<0,001)$. We didn't found any correlation between QAPCs and age at Glenn or Fontan operation in both groups, ventricular volumes and EF. In the 4 patients evaluated before and after Fontan the QAPCs decreased.

\section{Conclusions}

New CMR techniques allow a reliable quantification of APCs flow. It is higher in Glenn patients than in Fontan and is inversely correlated to $\mathrm{O} 2$ sat, to pulmonary branches diameters and flow and directly correlate to the cardiac output. HLHS is a risk factor for APCs. Prospective study are needed to evaluate the clinical significance of APCs

\section{Funding}

N/A.

\section{Authors' details}

'Pediatric cardiology and GUCH unit, Toscany Fondation Gabriel Monasterio, Massa, Italy. ${ }^{2}$ MRI Lab, FTGM, Pisa, Italy. ${ }^{3}$ sstitut of Clinical Physiology, Massa, Italy. ${ }^{4}$ Pediatric cardiac surgery, FTGM, Massa, Italy.

Published: 3 February 2015

doi:10.1186/1532-429X-17-S1-Q101

Cite this article as: Festa et al:: CMR evaluation of aorto-pulmonary

collaterals in Glenn and Fontan patients. Journal of Cardiovascular Magnetic Resonance 2015 17(Suppl 1):Q101. 